\title{
AMBIENTE INSTITUCIONAL E DIFUSÃO DO PROGRAMA SEGUNDO TEMPO: UMA ANÁLISE DA DIFUSÃO REGIONAL DE 2005 A 2009
}

\author{
Edmilson Santos dos Santos
}

Universidade Federal do Vale do São Francisco, Petrolina, Pernambuco, Brasil

\begin{abstract}
Resumo
Este estudo tem por objetivo verificar se o ambiente institucional nos municípios contribui para a difusão do Programa Segundo Tempo. Os municípios que compuseram a análise foram aqueles que receberam algum núcleo do PST de 2005 a 2009. As instituições selecionadas para a análise do ambiente institucional foram a Secretaria Municipal de Esporte, o Conselho Municipal de Esporte, o Conselho Municipal da Criança e a política de esporte prevista em Lei Orgânica. O ambiente institucional não se mostrou uma variável robusta para explicar a difusão do programa.
\end{abstract}

Palavras-chave: Políticas Públicas. Política Social. Esportes. Organização Institucional.

\section{Introdução}

s políticas públicas de esporte destinadas aos públicos infantil e
juvenil não reconhecem, até o presente momento, nenhuma condicionalidade, do tipo da que é experimentada na educação e na saúde, nem a legislação imputou ao gestor alguma obrigação positiva. Essa cobrança deve dar-se no plano político. Entretanto, essas políticas que conjugam criança, jovens e esporte não são plataformas decisivas à competição eleitoral; seus maiores beneficiários não possuem instrumentos de accountability [para essa análise ver O’Donnell (1998) e Ceneviva (2005)] capazes de premiar ou de impor sanções aos que não respondem adequadamente às preferências desses grupos, que guardam um gosto especial pelas atividades esportivas ${ }^{1}$, e os proces-

1-Não lançarei mão de nenhum recurso teórico para comprovação dessa premissa; apenas trarei à opinião pública os resultados de uma experiência de duas décadas com o ensino da educação física em escolas públicas da Região Metropolitana de 
sos democráticos participativos não são capazes de absorver suas preferências.

Suas demandas só podem chegar ao debate político por meio de representantes que não são fios condutores desinteressados. Não que sejam portadores de um desvio moral, mas porque atuam como sujeitos políticos dispostos, se necessário, a maximizar seus interesses ou a colocar preferências associadas ao público adulto em ação, aquilo que promove a suas plataformas políticas. Não é de se estranhar, então, que estudos que buscam identificar as preferências de bem-estar de jovens coloquem suas demandas numa situação inversa ao experimentado até pelos mecanismos de participação direta (SANTOS, 2010). O Orçamento Participativo em Porto Alegre, reconhecido como importante espaço de experimentação da participação popular na gestão do governo municipal, jamais conseguiu colocar entre as suas principais propostas às demandas do campo esportivo e, menos ainda, conjugar esporte e criança².

Nesse sentido, o que pode explicar a difusão do Programa Segundo Tempo entre os municípios brasileiros? Uma das explicações do novo institucionalismo (neoinstitucionalismo ${ }^{3}$ ) vai na direção de pensar o papel dos partidos políticos na difusão de programas. O partido que está no poder tem incentivos para garantir a adesão de políticas descentralizadas em municípios de sua base de apoio ${ }^{4}$. Como o Programa Segundo Tempo é um programa que exige contrapartida, poderíamos pensar que a capacidade fiscal do município poderia agir de forma a constranger adesões ${ }^{5}$. Outra forma de analisar esse quadro explicativo

Porto Alegre. Desconsiderá-la, aqui, em nome de um rigor metodológico, seria a negação da experiência como um campo frutífero de construção do conhecimento.

2-Esse ator não possui status cívico que o capacite a participar ativamente desses ambientes decisórios. Nesse caso, a crítica aos limites da participação evidencia a grande dificuldade de pensarmos a agregação de preferências individuais às escolhas do bem comum.

3-A premissa institucionalista aceita que o resultado da ação política pode ser explicado pelo somatório das preferências individuais. O novo institucionalismo busca compreender como as regras formais (normas, estruturas administrativas) e informais (ideias, valores) modelam o resultado da política pública.

4-Para essa análise, ver O papel dos partidos políticos na difusão do Programa Segundo Tempo (SANTOS, 2012b).

5- Para essa análise, ver paper apresentado na área temática Estado e Políticas Públicas, no $8^{\circ}$ Encontro da Associação Brasileira de Ciência Política, no grupo de 
é pensar na existência de instituições com capacidade de valorizar certas ideias e promover constrangimentos de forma a pressionar o decisor a fazer adesão ao programa.

O debate sobre o papel das instituições na modelagem do resultado e do conteúdo da política está bastante consolidado na ciência política. Isso indica que há o reconhecimento de que as instituições afetam as preferências nas escolhas públicas à medida que mediam a relação entre o Estado e a sociedade. Elas assumem a função de "reduzir incertezas, introduzir regularidade e estabilidade ao dia a dia, servir de guia para as interações humanas, propagar informação, determinar as estruturas de incentivos e ajudar as pessoas a decodificar o contexto social de forma a torná-las aptas para fazer escolhas e tomar decisões" (CAVALCANTE, 2011, p. 1790).

A agenda de pesquisa neoinstitucionalista está preocupada em identificar quais instituições importam para o resultado da política e como elas afetam as decisões (KALMANOVITZ, 2003; IMMERGUT, 2006; ARRETCHE, 2007; PERES, 2008; NASCIMENTO, 2009). Para essa vertente, não há espaço para compreender que o resultado seja a soma das preferências individuais (fatores endógenos) e que a estrutura social explique o resultado da política, como pretende o estruturalismo (THÈRET, 2003).

O novo institucionalismo obteve muito sucesso na literatura brasileira (SOUZA, 2007), e importantes trabalhos têm sido produzidos a fim de identificar o impacto das instituições no desenho das políticas públicas (ARRETCHE, 1999; SOUZA; CARVALHO, 1999; MENICUCCI; BRASIL, 2006; LUBAMBO, 2006; CÔRTES, 2007 e 2009; SILVA; CÔRTES, 2007; ARRETCHE; MARQUES, 2007; VASQUEZ, 2007). O novo institucionalismo pode ser compreendido a partir da existência de três vertentes analíticas: o institucionalismo da escolha racional, o institucionalismo sociológico e o institucionalismo histórico (HALL; TAYLOR, 2003).

O modelo de escolha racional pressupõe a existência de uma racionalidade capaz de balizar o comportamento dos decisores. Essa racionalidade seria estruturada por meio de planos coerentes, maximização das preferências, minimização dos custos de satisfação e

Políticas Públicas: O papel da capacidade fiscal per capita dos municípios na difusão do Programa Segundo Tempo/ME: uma análise da implementação do programa de 2005 a 2009 (SANTOS, 2012a). 
garantia da premissa da conectividade, ou seja, a existência de um completo ordenamento das alternativas (BAERT, 1997). O resultado da política seria uma escolha baseada em avaliações precisas de custos e de impacto. Todo esse processo é percebido como uma sequência lógica (racional) que tem nos decisores, modelo top down, seu principal personagem. A convicção dos decisores seria formada mediante informações suficientes à tomada de decisão, e suas inclinações políticas estariam suspensas por um conjunto de regras. Um dos princípios que norteiam esse modelo é a crença na burocracia como o tipo-ideal weberiano: um conjunto de regras que teria por objetivo impor limites à maximização do autointeresse (como uma forma de anular a efetivação das inclinações pessoais, dos desejos e das opiniões) e, assim, garantiria espaço para uma escolha puramente racional ${ }^{6,7}$.

O institucionalismo histórico tende a aceitar que as instituições são formadas por regras e convenções editadas por organizações formais e que acabam criando dependências futuras (path dependency ${ }^{8}$ ). Isso significa que decisões tomadas criam dificuldades (elevando os custos da transação) para que haja uma mudança de rumo. O exemplo mais nítido na área dos esportes é o Programa Segundo Tempo. Ele surge da união de dois programas do governo Fernando Henrique Cardoso (FERREIRA; CASSIOLATO; GONZALES, 2009); assim, seus custos de implementação (formulação de nova política, problemas de agenda e construção de novos arranjos burocráticos) criaram constrangimentos institucionais, e a possibilidade de ruptura aumentava os custos políticos (tempo para produzir um programa inovador no início do

6-Uma crítica importante à possibilidade de uma ação racional vem de Hayek (2007), um crítico importante do apriorismo, que aponta que, nesse modelo, a ação é bloqueada por informações limitadas. Esse problema seria equacionado com experimentações competitivas de longo prazo, como acontece nos mercados. Porém, para Ferejohn e Pasquino (2001, p. 5), "As evidências experimentais existentes em grande abundância sugerem que as pessoas se desviam sistematicamente das predições da teoria da escolha racional."

7-Rosenau (1993) questiona a possibilidade de um processo político ser baseado numa racionalidade moderna: eficiente, científica (alheia aos debates em torno dos valores) e com uma revisão à luz do feedback. Esse modelo pressupõe um tempo linear, informação completa, resultados previsíveis e um governo centralizador e blindado das pressões políticas, capaz de tomar todas as decisões com base em escolhas puramente técnicas.

8-Ver Fernandes (2002).

Pensar a Prática, Goiânia, v. 16, n. 1, p. 1-319, jan./mar. 2013 
governo): “[...] decisões tomadas no passado constrangem decisões futuras e limitam a capacidade dos governos de adotar novas políticas ou de reverter a rota das políticas." (SOUZA, 2007). Nas mudanças incrementais, os legados políticos influenciam escolhas futuras (HALL; TAYLOR, 2003).

O institucionalismo sociológico tenta ampliar os horizontes de entendimento do que seja a instituição. Para isso ele se sustenta por meio de três características. Primeiro, reconhece que símbolos, esquemas cognitivos e padrões morais fornecem padrões de significado que estruturam o campo de possibilidades da atuação dos indivíduos. Segundo, os decisores têm uma ação interacional com as instituições, com influências mútuas. Ao mesmo tempo em que as utilizam para guiar seu comportamento, interagem sobre elas transformando-as ao internalizarem elementos da cultura e princípios normativos (NASCIMENTO, 2009). Por último, uma nova prática institucional pode ser produzida não para garantir racionalidade, mas sim para auferir legitimidade a certas posições políticas.

Apesar da realidade apresentada, as instituições [principalmente aquelas de países onde elas estão consolidadas (FREY, 2000)] teriam um papel estabilizador, garantindo um padrão nas interações e não permitindo mudanças bruscas nas políticas, ao afetarem os comportamentos dos indivíduos (HALL; TAYLOR, 2003). Mediações são realizadas entre a estrutura social e o comportamento dos indivíduos de forma a diminuir as incertezas e deslocar a atenção da produção das políticas públicas proposta pela ortodoxia do individualismo metodológico (FEREJOHN; PASQUINO, 2001; THERET, 2003) ou, como destaca Ostrom (2007), as regras, normas e estratégias adotadas para estabelecer relação entre (e dentro) as organizações. Em resumo, as instituições podem modelar a definição dos decisores, não como uma variável condicional, mas por causa de regras, formais e informais, e do ambiente que ocupam papel importante na produção das políticas públicas (SOUZA, 2007).

A questão que se coloca é esta: o que justifica que essa temática (conjugar esporte e criança) atraia a atenção de governos se a norma não impõe uma obrigação objetiva ao gestor público: a garantia do direito ao esporte? Um ponto importante pode ser analisado a partir do valor que essa ideia ${ }^{9}$ - o esporte como promotor de bem-estar para

9-O debate em torno das ideias tem sido muito profícuo na política pública. Para um melhor entendimento, ver Faria (2003).

Pensar a Prática, Goiânia, v. 16, n. 1, p. 1-319, jan./mar. 2013 
crianças e jovens tem no imaginário da sociedade. Ela poderia funcionar como uma instituição, produzindo constrangimentos. Talvez essa ideia possa ser pensada como uma necessidade cultural na forma como é trabalhada no novo institucionalismo sociológico.

Não havendo mecanismos institucionais de agregação dos desejos e das preferências infantis ou juvenis de forma direta (uma república das crianças ou dos jovens ${ }^{10}$ ), precisamos apostar que seus interesses (ou ideias) possam reverberar de alguma forma entre os decisores políticos. Nesse caso, as instituições passam a ter um papel fundamental nesse processo.

A tese que procuramos levantar aqui é que a força dessa ideia [ideia no sentido que é dado pelo Multiple Streams Model] ${ }^{11}$, o esporte como um direito a ser garantido à criança ${ }^{12}$ está diretamente associada ao incremento dado pelas instituições ao ambiente institucional (político/cultural). Um ambiente que possa atuar, por conta de constrangimentos de várias ordens, na modelação de um cenário que coloque essas preferências na agenda política, construindo vetores que não podem ser desconsiderados pelo decisor (policy maker). Na vida real, as instituições não estão ali apenas modelando o comportamento dos atores (MARCH; OLSEN, 2008), garantindo legitimidade social (HALL; TAYLOR, 2003) ou cumprindo função estabilizadora (FREY, 2000) à agenda política. A sua existência seria também patrocinadora e legitimadora do ambiente político valorizando determinadas ideias no espaço público, produzindo um clima favorável a essa agenda. A mobilização da opinião pública tem um impacto positivo porque atrai a atenção de políticos (BURSTEIN, 2003; KINGDON, 2006). Ao mobilizar diferentes atores, a ideia esporte/criança permitiria uma maior fluidez na sociedade, criando um clima favorável (num formato reduzido no national mood do Multiple Streams) à produção de políticas públicas de esporte direcionadas às crianças. Esse clima construi-

10-Nem os processos de democracia participativa conseguem incorporar esses atores. Como construir a ideia de bem comum com a abdução desses atores de um tema que faz parte de seu pacote de preferências?

11-Um resumo do modelo pode ser encontrado na literatura brasileira em Capella (2007) e Zahariadis (2007).

12-Consideramos as justificativas sobre a saúde, melhoria do desempenho escolar e uma prática que não combina com o uso de droga apenas um recurso político para difundir essa idéia.

Pensar a Prática, Goiânia, v. 16, n. 1, p. 1-319, jan./mar. 2013 
ria um cenário em que a pauta esportiva direcionada à criança, principalmente, estaria ajudando ou facilitando a tomada de decisão.

A temática em pauta sugere pensar o ambiente institucional (não nos ocorre uma expressão mais significativa) a partir da confluência de duas áreas que teriam papel estratégico na formulação ou na difusão de políticas públicas na área esportiva: uma determinada ideia sobre o esporte, e a atenção à criança e ao jovem. Dificilmente encontraremos alguma tese que não reconheça o esporte como indispensável à formação da criança. A atenção à criança, principalmente após o Estatuto da Criança e do Adolescente, incorpora-o como um bem associado a sua existência e como condição sine qua non para o desenvolvimento da sociedade.

Dessa forma, as diferentes instituições, além de balizarem o campo de atuação dos atores políticos, promoveriam a difusão de determinadas ideias fundamentais de políticas públicas que seguidamente são secundarizadas diante de preferência do mundo dos adultos. Os constrangimentos construídos por um conjunto de instituições na difusão de determinadas ideias poderiam promover uma movimentação do governante em direção à produção de determinadas políticas públicas de baixo valor na competição eleitoral majoritária, como é o caso do Programa Segundo Tempo, mas que respondem a determinadas ideias com capacidade de mobilizar atenção.

O pressuposto básico que assumimos neste trabalho é que um ambiente institucional robusto (com diferentes atores institucionais que pautem os direitos da criança e ao esporte como um valor cultural importante à sociedade) criaria condições favoráveis à oferta de políticas públicas ao promover maior mobilização local em torno do tema. Ela, não necessariamente, seria o resultado de um contexto relacional, como propõe a abordagem das redes de Marques (2006), mas deste ambiente criado em torno da atenção à criança e do esporte. A política pública seria o resultado de uma vitória cívica [muito próxima ao entendimento trazido por Putnam (1996)] em que as ideias e as instituições cumpririam um papel estratégico na garantia do bem comum.

É possível destacar quatro instituições formais na configuração dessa realidade (ambiente institucional): uma burocracia estatal autônoma (porque exclusiva) capaz de potencializar a área esportiva e servir como arena de disputas, especificamente uma Secretaria Municipal de Esporte; um espaço capaz de receber demandas da sociedade e servir como um canal de intermediação de interesses na área esportiva, o 
Conselho Municipal de Esporte; uma instituição que teria como objetivo lutar pela garantia dos direitos das crianças, o Conselho Municipal da Criança e do Adolescente; e a existência de uma norma municipal capaz de apontar deveres ao gestor municipal no campo esportivo, a Lei Orgânica. Essas instituições seriam produto e produtoras de um clima de valorização do esporte como estratégia de atenção à criança na realidade local.

Muito embora a política de esporte direcionada às crianças possa ser produzida pela Secretaria de Educação, ou por outro órgão, é por uma secretaria específica de esporte que ela se fortalece sem precisar justificar sua importância com predicados pretensamente mais nobres. Como esfera produtora de políticas públicas, sua materialização no primeiro escalão de governo implica o estabelecimento de dotação orçamentária própria, de liberdade para receber demandas de atores esportivos, e a implementação de políticas que promovam culturalmente o esporte. Ela pode servir, ainda, como uma arena de disputa e de intermediação de interesses em torno da agenda esportiva. Estando subordinada a outro órgão, ela perde sua autonomia, e seu orçamento precisa ser negociado, fato esse que cria dificuldades à produção de políticas públicas esportivas.

A existência de um Conselho Municipal de Esporte indicaria uma grande mobilização societal em torno das políticas de esporte e uma rede de atores disseminando determinadas ideias. No caso do Conselho Municipal de Criança e do Adolescente, atores outros estariam mobilizados para garantir determinados direitos, dentre estes o direito ao esporte e ao lazer. A Lei Orgânica poderia não só referendar a mobilização feita em torno da temática esportiva como também impor obrigações aos gestores.

Uma região onde todas as cidades possuíssem a temática do esporte prevista na Lei Orgânica Municipal, Secretaria Municipal de Esporte, Conselho Municipal de Esporte e Conselho Municipal da Criança e do Adolescente teria melhores condições institucionais de promover constrangimentos positivos de forma a interferir na agenda decisional do que outra região onde nenhuma dessas instituições estivesse presente. Neste caso o resultado da política pública de esporte seria apenas o resultado da preferência do gestor público. 


\section{Metodologia}

Este estudo tem por objetivo verificar se o ambiente institucional contribui para a difusão do Programa Segundo Tempo. A ideia primeira, abandonada por conta da dificuldade de acessar um banco de dados com informações municipais, incorporava o município como unidade de análise. Como o documento do IBGE Perfil dos Municípios Brasileiros trazia as informações por região e por classe populacional incorporamos essas duas unidades de análise em nosso programa de estudo. As informações sobre o Programa Segundo Tempo foram buscadas diretamente nos relatórios publicados diretamente pelo sítio do Ministério do Esporte.

As instituições selecionadas para a análise do ambiente institucional foram a Secretaria Municipal de Esporte, o Conselho Municipal de Esporte, o Conselho Municipal da Criança e a política de esporte prevista em Lei Orgânica. Essas informações foram coletadas diretamente da Pesquisa de Informações Básicas Municipais - Perfil dos Municípios Brasileiros 2009 do IBGE. O percentual de difusão do Programa Segundo Tempo considera apenas os municípios que receberam, de 2005 a 2009, pelo menos um núcleo do programa proposto pelo gestor municipal.

O modelo metodológico utilizado para a análise estabeleceu valor a partir de uma hierarquia de posições, em termos de distribuição (percentual de instituição por região/estado e classe populacional), onde o melhor desempenho recebe o menor valor (1); e o pior, uma numeração subsequente ascendente $(2,3,4,5)$ para cada uma das instituições selecionadas. O desenho final, de forma a identificar a região com o melhor ambiente institucional, é o resultado do somatório de todas as posições alcançadas pelas instituições. A primeira colocação seria formada por aquele que obtivesse o menor valor, por conta de um maior número de instituições atuando nela, indicando um ambiente institucional mais robusto; e a pior, aquela em que essas instituições estariam menos presentes. A hipótese central é de que a difusão do Programa Segundo Tempo é maior na região onde o ambiente institucional é mais robusto, e vai diminuindo à medida que esse ambiente vai se tornando mais frágil (menos representativo). 


\section{Análise dos resultados}

Com relação à distribuição da Secretaria Municipal de Esporte, é possível identificar dois extremos bem nítidos: de um lado, está a Região Nordeste, que, em quase todas as classes de população, alcançou a pior distribuição, perdendo na primeira classe apenas para a Região Sul; de outro, está a Região Sudeste, que obteve o melhor resultado em cinco das sete classes populacionais. O segundo melhor resultado foi alcançado pela Região Centro-Oeste, seguida pela Região Norte e, por último, a Região Sul. A classe populacional que mais apresentou variação foi a Classe "G", com 59,6 pp. Esse é o resultado da diferença entre a Região Sudeste, $77,78 \%$ e a Região Nordeste, $18,18 \%$.

Tabela 1: Ordem de distribuição da Secretaria Municipal de Esporte exclusiva por classe populacional e região

\begin{tabular}{ccccccccccc}
\hline & \multicolumn{3}{c}{ Norte } & \multicolumn{2}{c}{ Nordeste } & \multicolumn{2}{c}{ Sudeste } & \multicolumn{2}{c}{ Sul } & \multicolumn{2}{c}{ Centro-Oeste } \\
\hline & $\%$ & Posição & $\%$ & Posição & $\%$ & Posição & $\%$ & Posição & $\%$ & Posição \\
\hline Classe A & 16,09 & 2 & 9,78 & 4 & 12,07 & 3 & 4,28 & 5 & 27,97 & 1 \\
Classe B & 14,61 & 3 & 9,95 & 5 & 18,63 & 2 & 11,34 & 4 & 26,32 & 1 \\
Classe C & 14,02 & 3 & 11,21 & 5 & 25,07 & 1 & 11,79 & 4 & 24,27 & 2 \\
Classe D & 19,47 & 3 & 12,27 & 5 & 35,71 & 1 & 20,83 & 2 & 15,28 & 4 \\
Classe E & 15,63 & 3 & 11,82 & 5 & 42,86 & 1 & 12,28 & 4 & 31,58 & 2 \\
Classe F & 22,22 & 4 & 4,55 & 5 & 61,02 & 1 & 37,21 & 3 & 50 & 2 \\
Classe G & 33,33 & 4 & 18,18 & 5 & 77,78 & 1 & 66,67 & 2 & 60 & 3 \\
\hline
\end{tabular}

Fonte: Perfil dos Municípios Brasileiros: IBGE, 2009.

Excetuando a Região Nordeste, todas as outras apresentam um aumento na participação de uma secretaria autônoma à medida que se avança em direção à Classe G. Em linhas gerais, é possível dizer que ainda é muito tímida a existência de uma secretaria autônoma para tratar do esporte na estrutura administrativa municipal. Como veremos abaixo, na análise intrarregional, é possível verificar, de uma maneira mais precisa, a forma como, em cada estado, essa variável tem sido assumida como espaço de poder.

Tabela 2: Ordem de distribuição do Conselho Municipal de Esporte por classe populacional e região

\begin{tabular}{lcccccccccc}
\hline & \multicolumn{3}{c}{ Norte } & \multicolumn{2}{c}{ Nordeste } & \multicolumn{2}{c}{ Sudeste } & \multicolumn{2}{c}{ Sul } & \multicolumn{2}{c}{ Centro-Oeste } \\
\hline & $\%$ & Posição & $\%$ & Posição & $\%$ & Posição & $\%$ & Posição & $\%$ & Posição \\
\hline Classe A & 2,29 & 4 & 0 & 5 & 4,46 & 2 & 30,17 & 1 & 4,2 & 3 \\
Classe B & 1,22 & 4 & 1,02 & 5 & 6,13 & 2 & 25,09 & 1 & 2,63 & 3 \\
Classe C & 3,74 & 4 & 1,72 & 5 & 8,83 & 3 & 25,76 & 1 & 10,68 & 2 \\
Classe D & 5,31 & 4 & 3,24 & 5 & 11,22 & 3 & 22,22 & 1 & 15,28 & 2 \\
Classe E & 6,25 & 5 & 6,36 & 4 & 21,43 & 3 & 43,86 & 1 & 26,32 & 2 \\
Classe F & 5,56 & 5 & 20,45 & 4 & 34,75 & 3 & 46,51 & 1 & 40 & 2 \\
Classe G & 66,67 & 2 & 18,18 & 5 & 55,56 & 3 & 100 & 1 & 50 & 4 \\
\hline
\end{tabular}

Fonte: Perfil dos Municípios Brasileiros: IBGE, 2009. 
Como observação preliminar, temos que a estrutura dos Conselhos Municipais de Esporte ainda é muito precária. Se estabelecermos como ponto de corte, para considerar um alcance razoável, um mínimo de $20 \%$ dos municípios possuindo conselhos, identificaremos que $57,14 \%$ dos cenários seriam classificados como frágeis. A Região Sul é a que melhor se apresenta na configuração dessa realidade: não possui nenhum cenário com menos de $20 \%$ de suas cidades com a estrutura do conselho, o que indica uma grande mobilização societal em torno das políticas públicas de esporte. Já a Região Nordeste parece ser a mais fragilizada: somente em um cenário apresenta um valor acima de $20 \%$ e, em quase todas as posições, exceto em duas, ocupa a última. As diferenças entre as Regiões Sudeste e Centro-Oeste não são elevadas, mas suficientes para dar uma vantagem à última. A Região Norte vem logo após, com apenas um cenário com mais de $20 \%$. Na análise nacional, a única região que apresenta um padrão consolidado é a Região Sul, que ocupa a primeira posição em todos os cenários. Para cada um das outras regiões, é preciso uma análise específica de cada cenário.

Tabela 3: Ordem de distribuição do Conselho Municipal da Criança e do Adolescente por classe populacional e região

\begin{tabular}{ccccccccccc}
\hline & \multicolumn{3}{c}{ Norte } & \multicolumn{2}{c}{ Nordeste } & \multicolumn{2}{c}{ Sudeste } & \multicolumn{2}{c}{ Sul } & \multicolumn{2}{c}{ Centro-Oeste } \\
\hline & $\%$ & Posição & $\%$ & Posição & $\%$ & Posição & $\%$ & Posição & $\%$ & Posição \\
\hline Classe A & 83,91 & 5 & 88,44 & 4 & 93,18 & 2 & 93,59 & 1 & 92,31 & 3 \\
Classe B & 85,39 & 4 & 82,91 & 5 & 91,41 & 3 & 93,13 & 2 & 94,74 & 1 \\
Classe C & 87,85 & 4 & 86,55 & 5 & 92,88 & 3 & 96,07 & 2 & 97,09 & 1 \\
Classe D & 80,53 & 5 & 91,67 & 4 & 95,24 & 2 & 97,22 & 1 & 94,44 & 3 \\
Classe E & 81,25 & 5 & 92,72 & 4 & 97,91 & 2 & 94,74 & 3 & 100 & 1 \\
Classe F & 88,89 & 5 & 93,18 & 3 & 98,31 & 2 & 100 & 1 & 90 & 4 \\
Classe G & 100 & 1 & 100 & 1 & 94,44 & 5 & 100 & 1 & 100 & 1 \\
\hline
\end{tabular}

Fonte: Perfil dos Municípios Brasileiros: IBGE, 2009.

A existência do Conselho Municipal da Criança e do Adolescente está bastante consolidada no Brasil inteiro. Não há um único cenário em que sua existência não esteja assegurada em mais de $80 \%$ dos municípios. Mesmo assim, são as Regiões Sul e Centro-Oeste que conquistaram, em quatro classes de tamanho da população, a primeira colocação na distribuição do Conselho. Os piores resultados estão na Região Norte, que possui apenas uma cidade que ultrapassa os $90 \%$. Abaixo desse percentual, há três classes populacionais na Região Nordeste. 
Tabela 4: Ordem de distribuição de Lei Orgânica que contempla política de esporte por classe populacional e região

\begin{tabular}{lcccccccccc}
\hline & \multicolumn{2}{c}{ Norte } & \multicolumn{2}{c}{ Nordeste } & \multicolumn{2}{c}{ Sudeste } & \multicolumn{2}{c}{ Sul } & \multicolumn{2}{c}{ Centro-Oeste } \\
\hline & $\%$ & Posição & $\%$ & Posição & $\%$ & Posição & $\%$ & Posição & $\%$ & Posição \\
\hline Classe A & 78,16 & 5 & 82,67 & 2 & 80,05 & 4 & 83,37 & 3 & 85,31 & 1 \\
Classe B & 87,64 & 1 & 77,55 & 5 & 83,58 & 3 & 85,22 & 2 & 78,95 & 4 \\
Classe C & 85,05 & 2 & 77,76 & 5 & 80,63 & 3 & 88,21 & 1 & 79,61 & 4 \\
Classe D & 85,84 & 3 & 84,49 & 5 & 86,39 & 2 & 86,11 & 4 & 88,89 & 1 \\
Classe E & 93,74 & 1 & 87,27 & 4 & 87,76 & 3 & 91,23 & 2 & 68,42 & 5 \\
Classe F & 88,89 & 3 & 93,18 & 2 & 88,14 & 4 & 95,35 & 1 & 80 & 5 \\
Classe G & 100 & 1 & 81,82 & 5 & 100 & 1 & 100 & 1 & 100 & 1 \\
\hline
\end{tabular}

Fonte: Perfil dos Municípios Brasileiros: IBGE, 2009.

Em termos de Lei Orgânica, há uma mudança importante no quadro que havíamos encontrado na análise das instituições anteriores. A Região Norte alcançou, em três classes populacionais, os melhores resultados. O mesmo aconteceu com as Regiões Sul e Centro-Oeste. O pior resultado é alcançado pela Região Nordeste, por obter a última classificação em quatro classes, e é a única que não conseguiu $100 \%$ nas cidades acima de 500.000 habitantes.

Tabela 5: Posição do ambiente institucional por classe de população

\begin{tabular}{lccccc}
\hline & Norte & Nordeste & Sudeste & Sul & $\begin{array}{c}\text { Centro- } \\
\text { Oeste }\end{array}$ \\
\hline Classe A & 5 & 4 & 3 & 2 & 1 \\
Classe B & 4 & 5 & 3 & 1 & 1 \\
Classe C & 4 & 5 & 3 & 1 & 2 \\
Classe D & 4 & 5 & 2 & 1 & 3 \\
Classe E & 4 & 5 & 1 & 3 & 2 \\
Classe F & 5 & 4 & 2 & 1 & 3 \\
Classe G & 2 & 5 & 4 & 1 & 3 \\
\hline
\end{tabular}

Fonte: Dados de pesquisa.

O resultado final permite fazer algumas observações importantes. A confluência dessas quatro variáveis na conformação do ambiente institucional permite fazermos a seguinte avaliação: a Região Sul apresenta o melhor resultado, pois, em cinco cenários, obteve a melhor colocação; a Região Nordeste apresentou o pior ambiente cultural na medida em que obteve, em cinco cenários, a pior classificação; a Região Centro-Oeste ocupou a segunda colocação, pois possui duas posições em primeiro lugar; a Região Sudeste, a terceira colocação; e a Região Norte, a quarta.

Nesse sentido, levando em consideração o ambiente institucional, a Região Sul estaria mais bem provida para garantir maior difusão do Programa Segundo Tempo. A Região Nordeste estaria em piores con- 
dições, pois apresenta o menor número de instituições atuando na esfera municipal. A considerar a variável ambiente institucional interveniente nesse processo de difusão do PST, a Região Sul estaria com a melhor colocação; e a Nordeste, com a pior.

Tabela 6: Distribuição do PST por classe populacional e região

\begin{tabular}{lrcrrrrrrrr}
\hline \multicolumn{2}{c}{ Norte } & \multicolumn{2}{c}{ Nordeste } & \multicolumn{2}{c}{ Sudeste } & \multicolumn{2}{c}{ Sul } & \multicolumn{2}{c}{ Centro-Oeste } \\
\hline Estado & Posição & Estado & Posição & Estado & Posição & Estado & Posição & Estado & Posição \\
\hline Clas. A & 0 & 5 & 22,81 & 3 & 29,82 & 2 & 40,35 & 1 & 7,05 \\
Clas. B & 3,45 & 5 & 25,86 & 3 & 29,31 & 2 & 32,76 & 1 & 8,62 \\
Clas. C & 1,39 & 5 & 34,72 & 1 & 34,72 & 1 & 23,61 & 3 & 5,56 \\
Clas. D & 2,11 & 5 & 30,53 & 2 & 37,89 & 1 & 26,32 & 3 & 3,16 \\
Clas. E & 3,45 & 5 & 27,59 & 2 & 37,93 & 1 & 22,41 & 3 & 8,62 \\
Clas. F & 6,19 & 4 & 25,66 & 2 & 46,90 & 1 & 15,93 & 3 & 5,31 \\
Clas. G & 8,57 & 4 & 34,29 & 2 & 42,86 & 1 & 2,86 & 5 & 11,4 \\
\hline
\end{tabular}

Fonte: Dados de pesquisa, IBGE.

A Região Sudeste destaca-se como a que melhor consegue difundir o programa para cinco classes populacionais $(C, D, E, F$ e G). Apesar de ter apenas uma classe populacional com o melhor desempenho (C), em outras quatro posições foi o segundo melhor desempenho. As classes populacionais de pior desempenho são aquelas localizadas na Região Norte, o eu demonstrando a grande dificuldade dessa região em atrair o programa.

Tabela 7: Ordem de distribuição do PST e do ambiente institucional por classe populacional e região

\begin{tabular}{|c|c|c|c|c|c|c|c|c|c|c|}
\hline & \multicolumn{2}{|c|}{ Norte } & \multicolumn{2}{|c|}{ Nordeste } & \multicolumn{2}{|c|}{ Sudeste } & \multicolumn{2}{|c|}{ Sul } & \multicolumn{2}{|c|}{ Centro-Oeste } \\
\hline & $\mathrm{AI}^{*}$ & PST & $\mathrm{AI}$ & PST & $\mathrm{AI}$ & PST & $\mathrm{AI}$ & PST & AI & PST \\
\hline Classe A & 5 & 5 & 4 & 3 & 3 & 2 & 2 & 1 & 1 & 4 \\
\hline Classe B & 4 & 5 & 5 & 3 & 3 & 2 & 1 & 1 & 1 & 4 \\
\hline Classe C & 4 & 5 & 5 & 1 & 2 & 1 & 1 & 3 & 2 & 4 \\
\hline Classe D & 4 & 5 & 5 & 2 & 1 & 1 & 1 & 3 & 3 & 4 \\
\hline Classe E & 4 & 5 & 5 & 2 & 2 & 1 & 3 & 3 & 2 & 4 \\
\hline Classe F & 5 & 4 & 4 & 2 & 4 & 1 & 1 & 3 & 3 & 5 \\
\hline Classe G & 2 & 4 & 5 & 2 & 3 & 1 & 1 & 5 & 3 & 3 \\
\hline
\end{tabular}

Fonte: Dados de pesquisa, IBGE; *AI - ambiente institucional.

O modelo criado para identificar se as instituições interferem na constituição ambiente institucional não foi adequado para justificar a difusão do Programa Segundo Tempo. Em apenas cinco cenários, ele demonstrou adequação com o resultado do programa: Classe A na Região Norte; Classe B na Região Sul; Classe E nas Regiões Sudeste e Sul; Classe G na Região Centro-Oeste. Ao isolarmos cada uma das instituições, verificamos que a Região Sudeste apresenta a mesma posição para seis cenários no que se refere à secretaria exclusiva, indi- 
cando uma possível correspondência. Ou seja, as secretarias municipais de esporte atuando para promover adesão ao programa. Porém, as prefeituras não são as entidades que mais estabelecem convênio com o Programa Segundo Tempo, o que bloqueia a força argumentativa de que o resultado poderia ser explicado a partir dessa variável. Não deixa de ser surpreendente que a Região Nordeste, apesar de ter um ambiente institucional frágil, tenha conseguido um excelente desempenho na difusão do programa. A Região Sul, apesar de apresentar o melhor ambiente institucional, não conseguiu resultado correspondente na difusão do programa. Para esse nível de análise, as instituições não importam na difusão do Programa Segundo Tempo.

\section{Conclusão}

Apesar de, do ponto de vista teórico, a convergência das quatro instituições apresentar-se como uma hipótese interessante na constituição de um ambiente mais adequado à implementação de políticas de esporte direcionadas às crianças, ela não se mostrou consistente quando confrontada com a realidade dos dados para explicar os resultados da difusão do Programa Segundo Tempo. Conforme pudemos perceber, não houve correspondência entre o modelo de análise e a difusão.

O ambiente institucional não importou na distribuição do Programa Segundo Tempo para justificar nem as primeiras nem as últimas posições. Nesse sentido, podemos concluir que, para esse nível de análise, a instituição não importou na difusão do Programa Segundo Tempo. Não podemos de deixar de considerar e de ponderar o fato do modelo não permitir incluir as instituições por município (e não por classe populacional). Este fator pode ter contribuído para o resultado encontrado.

Não obstante, é possível observar que a literatura institucionalista destaca que o modelo federalista implica em desigualdade de distribuição de recursos (ARRETCHE, 2010), tendo em vista que "a engenharia constitucional brasileira gerou um federalismo que incorpora múltiplos centros de poder e que pode ser caracterizado como um sistema complexo de dependência política e financeira entre esferas de governo" (SOUZA, 2001, p. 549). Este debate coloca a diversidade do resultado como uma conseqüência necessária à difusão de programas descentralizados. 
Institutional environment and spread of the program Segundo Tempo: an analysis of the performance from 2005 to 2009

\begin{abstract}
This study aims at verifying whether the institutional environment in municipalities contributes to the spread of the Program Segundo Tempo (PST). The municipalities that comprised the analysis were those who received some kernel of PST from 2005 to 2009. The institutions selected for the analysis of the institutional environment were the Municipal Sport Secretary, the Sports City Council, the City Council of the Child, and the politics of sport provided in the Organic Law. The institutional environment did not prove to be a robust variable for explaining the spread of the program.
\end{abstract}

Keywords: Public policies. Social policies, Sports. Institutional Organization.

Entorno institucional y la difusión del programa Segundo Tempo: un análisis desde 2005 hasta 2009

\title{
Resumen
}

Este estudio tiene como objetivo verificar si el entorno institucional en las ciudades contribuye a la propagación del Programa Segundo Tempo (PST). Los municipios que componen el análisis fueron los que recibieron algún núcleo del PST desde 2005 hasta 2009. Las instituciones seleccionadas para el análisis del entorno institucional fueron la Secretaría Municipal de Deportes, el Consejo Municipal de Desportes, el Consejo Municipal del Niño y la política del deporte dispuesta en La Ley Orgánica. El entorno institucional no se reveló una variable robusta para explicar la difusión del programa.

Palabras clave: Políticas Públicas. Políticas Sociales. Deportes. Organización Institucional.

\section{Referências}

ARRETCHE, M. A agenda institucional. Revista Brasileira de Ciências Sociais, São Paulo, v. 22, n. 64, p. 147-151, jun., 2007.

. Federalismo e igualdade territorial: uma contradição em termos?. Dados, Rio de Janeiro, v. 53, n. 3, p. 587-620, 2010.

. Políticas sociais no Brasil: descentralização em um Estado federativo. Revista Brasileira de Ciências Sociais, São Paulo, v. 14, n. 40, p.111-141. jun., 1999.

ARRETCHE, M.; MARQUES, E. Condicionantes locais da descentralização das políticas de saúde. In: HOCHMAN, G.; ARRETCHE, 
M.; MARQUES, E. (Orgs.) Políticas públicas no Brasil. Rio de Janeiro: Ed. FIOCRUZ, 2007. p. 173-204.

BAERT, P. Algumas limitações das explicações da escolha racional na ciência política e na sociologia. Revista Brasileira de Ciências Sociais, São Paulo, v. 12, n. 35, p. 47-63, fev., 1997.

BURSTEIN, P. The impact of public opinion on public policy: a review and an agenda. Political Research Quarterly, v. 56, n. 1, p. 2940, mar., 2003.

CAPELLA, A. C. N. Perspectivas teóricas sobre o processo de formulação de políticas públicas. In: HOCHMAN, G.; ARRETCHE, M.; MARQUES, E. (Orgs.) Políticas públicas no Brasil. Rio de Janeiro: FIOCRUZ, 2007. p. 87-122.

CAVALCANTE, P. Descentralização de políticas públicas sob a ótica neoinstitucional. RAP, Rio de Janeiro, v. 45, n. 6, p. 1781-1804, nov./dez., 2011.

CENEVIVA, R. Avaliação e accountability: a avaliação de políticas públicas e a introdução de mecanismos de controle social na gestão da política educacional e do Programa DST/AIDS no Estado de São Paulo. In: ENCONTRO DA ASSOCIAÇÃO NACIOAL DOS PROGRAMAS DE PÓS-GRADUAÇÃO EM ADMINISTRAÇÃO, 29, 2005, Brasília, DF, Anais ... Brasília: ANPAD, 2005.

CÔRTES, S. V. Introdução: atores, mecanismos e dinâmicas participativas. In: CÔRTES, S. V. (Org.) Participação e saúde no Brasil. Rio de Janeiro: FIOCRUZ, 2009. p. 19-39.

. Viabilizando a participação em conselhos de políticas públicas municipais: arcabouço institucional, organização do movimento popular e policy communities. In: HOCHMAN, G.; ARRETCHE, M.; MARQUES, E. (Orgs.) Políticas públicas no Brasil. Rio de Janeiro: FIOCRUZ, 2007. p. 125-143.

FARIA, C. A. P. Idéias, conhecimento e políticas públicas: um inventário sucinto das principais vertentes analíticas recentes. Revista Brasileira de Ciências Sociais, São Paulo, v. 18, n. 51, 21-29, fev., 2003. 
FEREJOHN, J.; PASQUINO, P. A teoria da escolha racional na ciência política: conceitos de racionalidade em teoria política. Revista Brasileira de Ciências Sociais, São Paulo, v. 16, n. 45, p. 5-24, fev., 2001.

FERNANDES, A. S. A. Path dependency e os estudos históricos comparados. BIB, São Paulo, n. 53, p. 79-102, 1. sem., 2002.

FERREIRA, H.; CASSIOLATO, M.; GONZALEZ, R. Uma experiência de desenvolvimento metodológico para avaliação de programas: o modelo lógico do Programa Segundo Tempo. Texto para Discussão n. 1369, IPEA, 2009.

FREY, K. Políticas públicas: um debate conceitual e reflexões à prática da análise de políticas públicas no Brasil. Planejamento e Políticas Públicas, Brasília, n. 21, p. 211-257, jun., 2000.

HALL, P. A.; TAYLOR, R. C. R. As três versões do neo-institucionalismo. Lua Nova, São Paulo, n. 58, p. 193-223, 2003.

HAYEK, F. v. The meaning of the Welfare State. In: SBATIER, P. (Org.) Theories of the policy process. Cambridge, MA: Westriew Press, 2007. p. 90-95.

IMMERGUT, E. M. O núcleo teórico do novo institucionalismo. In: SARAIVA, E.; FERRAREZI, E. (org.) Políticas públicas. Brasília: ENAP, 2006. p. 155-195.

KALMANOVITZ, S. El institucionalismo como escuela. Revista de Economía Institucional, Bogotá, v. 5, n. 9, p. 189-212, 2003.

KINGDON, J. Como chega a hora de uma idéia?. In: SARAIVA, E.; FERRAREZI, E. (Org.) Políticas públicas. Brasília: ENAP, 2006. p. 219-224.

LUBAMBO, C. W. Desempenho da gestão pública: que variáveis compõem a aprovação popular em pequenos municípios?. Sociologias, Porto Alegre, a. 8, n. 16, p. 86-125, jul./dez., 2006.

MARCH, J. G.; OLSEN, J. P. Neo-institucionalismo: fatores organizacionais na vida política. Sociologia Política, Curitiba, v. 16, n. 31, p. 121-142, nov., 2008. 
MARQUES, E. C. Redes sociais e poder no Estado brasileiro: aprendizados a partir de políticas urbanas. Revista Brasileira de Ciências Sociais, São Paulo, v.21, n.60, p.15-41, fev., 2006.

MENICCUCI, T. M. G.; BRASIL, F. P. D. Construção de agendas e inovações institucionais: análise comparativa da reforma sanitária e da reforma urbana. Texto para Discussão n. 24, 2006, BH, Escola de Governo da Fundação João Pinheiro.

NASCIMENTO, E.O. Os novos institucionalismos na ciência política contemporânea e o problema da integração teórica. Revista Brasileira de Ciência Política, Brasília, n. 1, p. 95-121, jan./jun., 2009.

O'ODNNELL, G. Accountability horizontal e novas poliarquias. Lua Nova, São Paulo, n. 44, p. 27-54, 1998.

OSTROM, E. Institutional rational choise. An assessment of the Institutional Analysis and Development Framework. In. SABATIER, P. (Org.) Theories of the policy process. Cambridge, MA: Westview, 2007, p. 21-54.

PERES, P. S. Comportamento ou instituições? A evolução histórica do neo-institucionalismo da ciência política. Revista Brasileira de Ciências Sociais, São Paulo, v. 23, n. 68, p. 53-68, out., 2008.

PUTNAM, R. D. Comunidade e democracia: a experiência da Itália moderna. Rio de Janeiro: Fundação Getúlio Vargas, 1996.

ROSENAU, P. V. Anticipating a post-modern policy current?. Policy Current, Arizona, vol. 3, n. 2, p. 1-4, maio, 1993.

SANTOS, E. S. O papel da capacidade fiscal per capita dos municípios na difusão do Programa Segundo Tempo/ME: uma análise da implementação do programa de 2005 a 2009. Disponível em: http://www.starlinetecnologia.com.br/abcp2012/arquivos/28_6_2012_15_19_14.pdf. Acesso em 05 ago. 2012.

. O papel dos partidos políticos na difusão do Programa Segundo Tempo. Licere, Belo Horizonte, vol. 15, n. 3, set., 2012 b. 
SANTOS, F. C. Questões teóricas e metodológicas para os estudos de políticas públicas de lazer: alguns subsídios. Licere, Belo Horizonte, v. 13, n. 2. p. 1-22, jun., 2010.

SILVA, J. S.; CÔRTES, S. V. Interação sindicalismo-governo na Reforma da Previdência Brasileira. In: HOCHMAN, G.; ARRETCHE, M.; MARQUES, E. (Orgs.) Políticas públicas no Brasil. Rio de Janeiro: FIOCRUZ, 2007. p. 125-143.

SOUZA, C. Estado da arte da pesquisa em políticas públicas. In: HOCHMAN, G.; ARRETCHE, M.; MARQUES, E. (Orgs.) Políticas públicas no Brasil. Rio de Janeiro: FIOCRUZ, 2007. p. 65-86.

- Federalismo e descentralização na Constituição de 1988: processo decisório, conflitos e alianças. Dados, Rio de Janeiro, vol.44, n.3, p. 513-560, 2001.

SOUZA, C.; CARVALHO, I. M. M. Reforma do Estado, descentralização e desigualdades. Lua Nova, São Paulo, n. 48, p. 187-211, 1999.

THÉRET, B. As instituições entre as estruturas e as ações. Lua Nova, São Paulo, n. 58, p. 225-254, 2003.

VASQUEZ, D. A. Desigualdades interestaduais no financiamento da educação: o caso do Fundef. In: HOCHMAN, G.; ARRETCHE, M.; MARQUES, E. (Orgs.) Políticas públicas no Brasil. Rio de Janeiro: FIOCRUZ, 2007. p. 245-274.

ZAHARIADIS, N. The Multiple Streams Framework: structure, limitations, prospects. In: SBATIER, Paul (org.) Theories of the policy process. Cambridge, MA: Westriew Press, 2007. p. 65-92.

Recebido em: 01/09/2011

Revisado em: 13/01/2012

Aprovado em: 17/05/2012

Endereço para correspondência

profedsantos@yahoo.com.br

Edmilson Santos dos Santos

Universidade Federal do Vale do São Francisco

Av. José de Sá Maniçoba, s/n

Centro - Petrolina, PE, CEP 56304-205

Pensar a Prática, Goiânia, v. 16, n. 1, p. 1-319, jan./mar. 2013 